Chapman University

Chapman University Digital Commons

Pharmacy Faculty Articles and Research

School of Pharmacy

$12-19-2017$

\title{
Evolving Role of Non-Statin Therapy for the Management of Dyslipidemia and Cardiovascular Risk Reduction: Past, Present, and Future
}

\author{
Evan M. Sisson \\ Virginia Commonwealth University \\ Lauren Pamulapati \\ Virginia Commonwealth University \\ John D. Bucheit \\ Virginia Commonwealth University \\ Michael S. Kelly \\ Chapman University,mkelly@chapman.edu \\ Dave L. Dixon \\ Virginia Commonwealth University
}

Follow this and additional works at: https://digitalcommons.chapman.edu/pharmacy_articles

\section{Recommended Citation}

Sisson EM, Pamulapati L, Bucheit JD, Kelly MS, Dixon DL. Evolving role of non-statin therapy for the management of dyslipidemia and cardiovascular risk reduction: Past, present, and future. Pharmacotherapy. 2017;38(2):164-171. doi:10.1002/phar.2074

This Article is brought to you for free and open access by the School of Pharmacy at Chapman University Digital Commons. It has been accepted for inclusion in Pharmacy Faculty Articles and Research by an authorized administrator of Chapman University Digital Commons. For more information, please contact laughtin@chapman.edu. 


\section{Evolving Role of Non-Statin Therapy for the Management of Dyslipidemia and Cardiovascular Risk Reduction: Past, Present, and Future}

Comments

This is the accepted version of the following article:

Sisson EM, Pamulapati L, Bucheit JD, Kelly MS, Dixon DL. Evolving role of non-statin therapy for the management of dyslipidemia and cardiovascular risk reduction: Past, present, and future. Pharmacotherapy. 2017;38(2):164-171. doi:10.1002/phar.2074

which will be published in final form at DOI: 10.1002/phar.2074. This article may be used for noncommercial purposes in accordance with Wiley Terms and Conditions for Self-Archiving.

\section{Copyright}

Wiley 
DR EVAN SISSON (Orcid ID : 0000-0003-3961-853X)

DR DAVE L. DIXON (Orcid ID : 0000-0001-7560-9521)

Article type : Invited Commentary

Evolving Role of Non-Statin Therapy for the Management of Dyslipidemia and Cardiovascular Risk Reduction: Past, Present, and Future

${ }^{1}$ Evan M. Sisson, ${ }^{1}$ Lauren Pamulapati, ${ }^{1}$ John D. Bucheit, ${ }^{2}$ Michael S. Kelly, ${ }^{1}$ Dave L. Dixon

${ }^{1}$ Department of Pharmacotherapy \& Outcomes Science, Virginia Commonwealth University School of Pharmacy, Richmond, Virginia

${ }^{2}$ Department of Pharmacy Practice, Chapman University School of Pharmacy, Irvine, California

Corresponding Author:

Dave L. Dixon

Associate Professor, Department of Pharmacotherapy \& Outcomes Science

Virginia Commonwealth University School of Pharmacy

410 N. 12th Street, PO Box 980533

Richmond, VA 23298-0533

Phone: (804) 628-3784

Email: dldixon@vcu.edu

This article has been accepted for publication and undergone full peer review but has not been through the copyediting, typesetting, pagination and proofreading process, which may lead to differences between this version and the Version of Record. Please cite this article as doi: 10.1002/phar.02074

This article is protected by copyright. All rights reserved. 
Conflict of interest: The authors have nothing to disclose.

\author{
Funding: none
}

Running Title: Role of Non-Statin Therapy

Key words: cardiovascular disease, guidelines, dyslipidemia, statins, ezetimibe, PCSK9 inhibitors

\title{
Background
}

A plethora of evidence supports the use of statin therapy for primary and secondary prevention of atherosclerotic cardiovascular disease (ASCVD), yet residual risk among high-risk patients receiving statin therapy remains high. ${ }^{1}$ Moreover, statin-associated muscle symptoms and other statin-associated adverse effects (e.g., increased risk of diabetes mellitus) limit the use of statins in high-risk patient populations. ${ }^{2}$ Of particular concern are individuals with established ASCVD, familial hypercholesterolemia (FH), or diabetes mellitus plus multiple ASCVD risk factors, all of whom require high-intensity statins, which are more commonly associated with an increased risk of adverse effects. ${ }^{2,3}$ Consequently, there has been considerable interest in the use of combination lipid-lowering therapy to reduce ASCVD risk beyond that achievable with statin therapy alone.

The 2013 American College of Cardiology(ACC)/American Heart Association(AHA) Guideline on the Treatment of Blood Cholesterol to Reduce Atherosclerotic Cardiovascular Risk in Adults triggered a significant paradigm shift away from the previous Adult Treatment Panel III Cholesterol

Guidelines. ${ }^{4,5}$ Importantly, the guideline authors found no data for or against low-density lipoprotein cholesterol (LDL-C) treatment goals, which led to the establishment of four statin benefit groups and the recommendation to use moderate- to high-intensity statins in those groups. Limited recommendations were provided regarding the use of non-statins due to the lack of randomized controlled trial (RCT) evidence to support the effectiveness of these therapies to further reduce

This article is protected by copyright. All rights reserved. 
ASCVD risk when used in combination with statin therapy. Instead, the guidelines recommended that clinicians reinforce adherence to statin therapy and lifestyle modification in patients with an insufficient response to statin therapy, and provided recommendations on only the safety of nonstatins. Non-statins should only be considered in high-risk patients (clinical ASCVD, LDL-C $\geq 190 \mathrm{mg} / \mathrm{dL}$, diabetes mellitus) who have a suboptimal response to statins and/or are intolerant to statin therapy.

In 2014, the National Lipid Association (NLA) released recommendations that endorsed traditional treatment goals and advocated non-HDL-C as the primary treatment goal over LDL-C. ${ }^{6}$ Additionally, the decision to initiate statin therapy was based on ASCVD risk categories (low, moderate, high, very high) and treatment thresholds for initiating drug therapy, versus the statin benefit group approach recommended by the ACC/AHA. The NLA recommendations were also more inclusive of non-statins and their potential to be used as adjunct therapy to achieve non-HDL-C goals, despite a lack of robust evidence from prospective RCT to support a clinical benefit when used in combination with statin therapy.

Much has changed since publication of the 2013 ACC/AHA cholesterol guideline and NLA patient-centered recommendations. Two novel lipid-lowering therapies, alirocumab and evolocumab, have been approved by the United States Food and Drug Administration (FDA), and the available evidence supporting the use of non-statins has expanded. This subsequently led to a shift toward greater consideration for LDL-C and non-HDL-C treatment goals. The rapid pace at which the management of dyslipidemia has evolved in recent years has led to confusion among clinicians about the current status of treatment goals and, even more importantly, the role of non-statins. Our commentary will discuss the recent evidence and recommendations regarding the role of non-statins in combination with statins, and the remaining questions about the future of dyslipidemia management.

This article is protected by copyright. All rights reserved. 


\section{Clinical Guideline Updates on the Use of Non-Statins}

Following publication of the ACC/AHA cholesterol guideline and NLA patient-centered recommendations, two novel proprotein convertase subtilisin/kexin type 9 (PCSK9) inhibitors, alirocumab and evolocuamb, were approved by the FDA in 2015. Additionally, the Improved Reduction of Outcomes: Vytorin Efficacy International Trial (IMPROVE-IT) trial was the first to demonstrate a reduced risk of ASCVD by adding a non-statin (ezetimibe) to background statin therapy in patients with recent acute coronary syndrome (ACS). ${ }^{8}$ As a result, an Expert Consensus Decision Pathway (ECDP) on the role of non-statins was published in 2016 to guide clinical decision making on the use of non-satins in the four statin benefit groups of the 2013 ACC/AHA cholesterol guideline. ${ }^{9}$ Furthermore, recommendations were made in favor of treatment goals for LDL-C and non-HDL-C. These recommendations were endorsed by the NLA.

Shortly thereafter, the Further Cardiovascular Outcomes Research with PCSK9 Inhibition in Subjects with Elevated Risk (FOURIER) trial demonstrated that adding evolocumab to background statin therapy reduced the risk of cardiovascular events in a secondary prevention population. ${ }^{10}$ As such, a 2017 Focused Update of the 2016 Non-Statin ECDP was published to reflect the findings of the FOURIER trial. ${ }^{11}$ The NLA also released additional recommendations with a specific focus on appropriate patient selection for using PCSK9 inhibitors. ${ }^{12}$ Table 1 provides a summary of current guidelines and recommendations.

The Non-Statin ECDP provided clinicians with a clearer picture of which patients are potential candidates for non-statins to further reduce LDL-C. Most importantly, the recommendations were clear about which non-statins should be routinely considered in clinical practice.

This article is protected by copyright. All rights reserved. 


\section{Preferred Non-Statin Therapies}

Cholesterol Absorption Inhibitors (Bile Acid Sequestrants, Ezetimibe)

Reduction of dietary cholesterol absorption has long been a strategy to reduce circulating LDL-C levels. Although these agents effectively lower LDL-C level, data supporting ASCVD risk reduction has often been incomplete or unavailable. Bile acid sequestrants (BAS), including colestipol, cholestyramine, and colesevelam, lower LDL-C by 10-15\%; however, cardiovascular outcomes data are limited to only monotherapy use ${ }^{11}$ Nevertheless, the Non-Statin ECDP recommended BAS as an alternative for patients intolerant to ezetimibe who require $<25 \%$ reduction to reach LDL-C and non-HDL-C goals and have triglyceride (TG) levels below $300 \mathrm{mg} / \mathrm{dL} .{ }^{10}$ Additionally, BAS remain the drug of choice for pregnant women at high ASCVD risk. ${ }^{9}$

Ezetimibe is generally well tolerated and lowers LDL-C by as much as $25 \%$ when used in combination with statins; however, the lack of definitive cardiovascular benefit previously limited its widespread adoption. The combination of simvastatin-ezetimibe was compared to placebo in both the Simvastatin and Ezetimibe in Aortic Stenosis (SEAS) and Study of Heart and Renal Protection (SHARP) trials with mixed results. ${ }^{13,14}$ Although the SEAS trial found no benefit in patients with aortic stenosis, the SHARP trial demonstrated a $17 \%$ reduction in the risk of major cardiovascular events in patients with chronic kidney disease. However, isolating the actual effect of ezetimibe was difficult due to the lack of a statin-only comparator group. The Ezetimibe and Simvastatin in Hypercholesterolemia Enhances Atherosclerosis Regression (ENHANCE) trial concluded that adding ezetimibe to background statin therapy in patients with heterozygous FH slightly increased carotid intima media thickness, a surrogate marker of ASCVD risk, compared to statin monotherapy; however, it has been suggested that inclusion of patients with longstanding prior statin therapy, combined with the short trial duration, may have led to a spurious conclusion about ezetimibe. ${ }^{15,16}$

This article is protected by copyright. All rights reserved. 
The benefit of adding ezetimibe to statin therapy was finally addressed by the IMPROVE-IT trial, which compared the combination of simvastatin plus ezetimibe to simvastatin alone in patients who were within 10 days of an acute coronary syndrome (ACS) event. ${ }^{8}$ After 7 years of follow-up, the combination resulted in a modest, but statistically significant, reduction in the primary composite endpoint of death from cardiovascular causes, major coronary event, or nonfatal stroke. Although these data appear to support ezetimibe, the absolute reduction was modest and primarily driven by a reduction in coronary revascularization and nonfatal myocardial infarction. Use of a moderateintensity statin (simvastatin $40 \mathrm{mg} /$ day) also made the results difficult to extrapolate to patients who receive high-intensity atorvastatin or rosuvastatin after an ACS event. Consequently, the FDA did not approve a secondary prevention indication for ezetimibe and the fixed dose combination with simvastatin. ${ }^{17}$

PCSK9 Inhibitors

The PCSK9 inhibitors, alirocumab and evolocumab, were approved by the FDA in 2015 for individuals with FH or clinical ASCVD who are receiving maximally tolerated statin therapy and require additional LDL-C level lowering. ${ }^{7}$ Both alirocumab and evolocumab lower LDL-C level by up to $60 \%$ on top of what can be achieved with statin therapy. The exact role of PCSK9 inhibitors was initially unclear because these therapies were not approved until after release of the $2013 \mathrm{ACC} / \mathrm{AHA}$ cholesterol guideline, and clinical outcomes data were unavailable on their market launch. Furthermore, the lack of a universal definition for "maximally tolerated statin" and specific thresholds for sufficient LDL-C lowering led to more ambiguity about the role of PCSK9 inhibitors. There were also economic concerns given the average wholesale price of nearly $\$ 14,000$ per year. ${ }^{18}$

This article is protected by copyright. All rights reserved. 
Guidance on the use of PCSK9 inhibitors was provided in the 2016 Non-Statin ECDP, which recommended PCSK9 inhibitors as a second-line option in those with clinical ASCVD and comorbidities (e.g., diabetes) and only as a first-line option in those with baseline LDL-C $\geq 190$ $\mathrm{mg} / \mathrm{dL} .{ }^{9}$ Shortly thereafter, the FOURIER trial demonstrated that adding evolocumab to background moderate- or high-intensity statin therapy reduced LDL-C level by an additional $60 \%$ and, more importantly, reduced the risk of major adverse cardiovascular events by $15 \%$ in a secondary prevention population with stable ASCVD. ${ }^{10}$ In response to these data, the ACC published a 2017 Focused Update to the 2016 Non-Statin ECDP and the NLA released recommendations regarding the use of PCSK9 inhibitors (Table 1). ${ }^{11,12}$

Although PCSK9 inhibitors have clinical outcomes data supporting their use in high-risk patients, many concerns remain. First, there was no mortality benefit in the FOURIER trial despite patients achieving a median LDL-C level of $30 \mathrm{mg} / \mathrm{dL}$, the lowest median level of LDL-C ever achieved in a RCT. ${ }^{10}$ This lack of mortality benefit may have been due to the short duration of follow-up (26 months) and the low overall cardiovascular mortality rate $(<2 \%)$, which may have made it more difficult to demonstrate a mortality benefit. Furthermore, access to PCSK9 inhibitors remains challenging, even in appropriate patients, due to the significant acquisition costs and unfavorable cost-effectiveness profile. ${ }^{18,19}$ Obtaining approval from insurance companies for PCSK9 inhibitors requires highly detailed documentation and administrative support to process prior authorizations. ${ }^{20}$ Access is likely to improve given the FDA recently granted evolocumab an indication for use as adjunct to diet, alone or with other lipid-lowering therapies, to reduce the risk of cardiovascular events in patients with established ASCVD. ${ }^{21}$

This article is protected by copyright. All rights reserved. 


\section{Current Role of Other Non-Statin Therapies}

Fibrates

The fibrates, gemfibrozil and fenofibrate derivatives, are primarily considered TG-lowering therapies but are also effective at reducing non-HDL-C level. Although fibrates have been shown to reduce ASCVD risk when used as monotherapy in placebo-controlled trials, only the Action to Control Cardiovascular Risk in Diabetes (ACCORD-Lipid trial prospectively evaluated the utility of adding a fibrate to statin therapy in patients with diabetes. ${ }^{22,23}$ Surprisingly, the combination of fenofibrate and simvastatin did not reduce ASCVD risk when compared to simvastatin monotherapy; however, the subgroup of patients with TG levels $\geq 204 \mathrm{mg} / \mathrm{dL}$ and HDL-C levels $\leq 34 \mathrm{mg} / \mathrm{dL}$ had lower cardiovascular event rates with combination therapy compared to statin monotherapy. ${ }^{22}$ Similar results were observed in a 5-year follow-up study of the ACCORD-Lipid trial. ${ }^{24}$ Despite these data, the American Diabetes Association recommends that clinicians consider adding fenofibrate to statin therapy in patients with elevated TG and low HDL-C levels. ${ }^{25}$ Fibrates are not, however, a preferred non-statin in the Non-Statin ECDP given they primarily lower TG and not LDL-C. ${ }^{11}$

Omega-3 Fatty Acids

Omega-3 fatty acids (O3FA) are primarily TG-lowering therapies containing a combination of the long-chain fatty acids, docosahexaenoic acid (DHA) and/or eicosapentaenoic acid (EPA). Of the FDA-approved products, omega-3 ethyl esters and omega-3 carboxylic acids contain both DHA and EPA, whereas icosapent ethyl contains only EPA. ${ }^{23}$ Although low-dose O3FA appears to modestly reduce ASCVD risk and mortality in patients with heart failure, there is little evidence to support adding O3FA to statin therapy to reduce ASCVD risk. $^{23}$ The only available data are from the Japan EPA Lipid Intervention Study (JELIS) trial, which found a reduction in cardiovascular events with EPA $1.8 \mathrm{~g} /$ day on top of background statin therapy, compared to statin therapy alone. ${ }^{26}$ However, the

This article is protected by copyright. All rights reserved. 
study did not include a placebo group, and the study population was enrolled entirely from Japan, limiting its generalizability. A recent meta-analysis found a $9 \%$ reduction in the risk of sudden cardiac death with O3FA supplementation, yet this was primarily influenced by clinical trials conducted before the "statin era" ${ }^{27}$ The inconsistent findings in secondary prevention with O3FA led to the AHA Scientific Advisory Statement recommendation that it is "reasonable" to use O3FA in secondary prevention ${ }^{28}$; however, the NLA recommended that O3FA ( $2-4 \mathrm{~g} /$ day) be limited only to the management of very high hypertriglyceridemia (TG $\geq 500 \mathrm{mg} / \mathrm{dL}$ ). ${ }^{6}$ Until additional evidence for ASCVD reduction is available, O3FA should be limited to patients with hypertriglyceridemia primarily to lower TG level and reduce the risk of acute pancreatitis.

Niacin

Niacin (nicotinic acid) has been widely used for primary and secondary ASCVD risk reduction until recently. Unfavorable results from the Heart Protection Study 2-Treatment of HDL to Reduce the Incidence of Vascular Events (HPS2-THRIVE) and Atherothrombosis Intervention in Metabolic Syndrome with Low HDL/High Triglycerides: Impact on Global Health Outcomes (AIM-HIGH) trials prompted the authors of the 2017 Focused Update of the Non-Statin ECDP to conclude that there are "no clear indications for the routine use of niacin preparations as additional non-statin therapies" ${ }^{11,29,30}$ Others have pointed out that these results differ from previous studies and may not accurately describe the role and potential benefits of niacin in addition to statin therapy. ${ }^{31}$ Differences in trial design, patient selection, niacin formulation, and dosing may all have contributed to the observed results. Like fibrates, the benefits of niacin may depend on the population studied and their pattern of dyslipidemia. Niacin appears to most benefit patients with an atherogenic lipoprotein phenotype, represented by small, dense LDL-C particles, and high TG and low HDL-C levels, whereas such lipid profiles were not typical of patients enrolled in the HPS2-THRIVE and AIMHIGH trials. Importantly, the primary aim of these recent studies was to determine the impact of

This article is protected by copyright. All rights reserved. 
niacin on residual risk in patients treated optimally with statin therapy. Although niacin should not be used routinely to reduce residual ASCVD risk in patients taking statins, there are likely subgroups, such as those with an atherogenic lipoprotein phenotype, who may benefit. As with fibrates and O3FAs, the challenge is to design clinical trials to accurately determine which patients may benefit most from non-statin therapy.

\section{Remaining Questions and Future Directions}

Although it is important not to underestimate the significant progress made in our understanding of the role of combination lipid-lowering therapy, there remain many unanswered questions. The most obvious of which is, "how low is too low?" when it comes to lowering LDL-C level in high-risk populations. The LDL-C levels achieved in both the IMPROVE-IT and FOURIER trials were exceedingly low compared to previous lipid-lowering studies, yet the absolute benefit was relatively modest, and no mortality benefit was observed. ${ }^{8,10}$ Importantly, there were no observed safety concerns during the median follow-up of 6 years and 2.2 years in the IMPROVE-IT and FOURIER trials, respectively. A prespecified post hoc analysis of the FOURIER trial showed that $41 \%$ of enrolled subjects achieved an LDL-C level $<50 \mathrm{mg} / \mathrm{dL}$, and a cardiovascular benefit was maintained down to LDL-C levels below $10 \mathrm{mg} / \mathrm{dL}$ with no signal for harm. ${ }^{32}$ As such, there now appears to be sufficient evidence to support the safety of lowering LDL-C levels to very low levels, yet longer-term safety data are still warranted.

A related question is whether or not defined treatment goals for $L D L-C$ and non-HDL-C should be preferred over the fixed-dose statin, risk-based approach recommended in the 2013 ACC/AHA cholesterol guideline. Baseline LDL-C levels in the IMPROVE-IT and FOURIER trials were reasonably well controlled at $93 \mathrm{mg} / \mathrm{dL}$, yet LDL-C levels well below $70 \mathrm{mg} / \mathrm{dL}$ were easily achieved and provided additional reduction in ASCVD risk. ${ }^{8,10}$ These data contributed to the 2017 Non-Statin

This article is protected by copyright. All rights reserved. 
ECDP recommendation that clinicians give consideration to treatment goals for LDL-C and non-HDL-

C. ${ }^{11}$ The remaining question is whether or not an LDL-C goal of $<70 \mathrm{mg} / \mathrm{dL}$ is sufficient for the highest risk patients. Some clinical practice guidelines have even advocated for LDL-C goals below $55 \mathrm{mg} / \mathrm{dL}$ in such patients. ${ }^{33}$ For now, treatment goal decisions should be made based on patient preferences, ASCVD risk factors, potential for polypharmacy, and prescription affordability.

Despite the favorable outcomes observed with both ezetimibe and PCSK9 inhibitors in combination with statins, there remains a high degree of residual cardiovascular risk in patients with established ASCVD. It is important to recognize that the absolute benefit with ezetimibe in the IMPROVE-IT trial was modest and only observed after a median follow-up of 6 years. ${ }^{8}$ Although evolocumab demonstrated a significant benefit in just 2.2 years, the absolute benefit was arguably modest when you consider its cost and the related barriers to access. ${ }^{10}$ Given our ability to now achieve very low levels of LDL-C, therapies aimed at reducing elevated levels of TG and/or raising low HDL-C levels to reduce residual cardiovascular risk remain an area of interest.

Elevated TG levels have consistently been associated with increased ASCVD risk, yet the role of TG as an independent risk factor remains controversial. ${ }^{23}$ As such, there are ongoing clinical trials to evaluate the potential of TG-lowering therapies to reduce residual risk, as well as several novel therapies currently in development. Both the Reduction of Cardiovascular Events with EPAIntervention Trial (REDUCE-IT) and Outcomes Study to Assess Statin Residual Risk Reduction with Epanova in High CV Risk Patients with Hypertriglyceridemia (STRENGTH) trials are randomized clinical outcome trials evaluating O3FA prescription products, icosapent ethyl and omega-3 carboxylic acids, in patients at high ASCVD risk with moderately elevated levels of TG receiving background statin therapy. ${ }^{23}$ Novel therapies include an antisense oligonucleotide (volanesorsen) and angiopoietin-like protein (ANGTL) 3 inhibitor (evinacumab), which are both currently in phase III and II clinical trials, respectively. Lastly, a highly potent and selective peroxisome proliferator-

This article is protected by copyright. All rights reserved. 
activated receptor- $\alpha$ agonist (pemafibrate) is currently being evaluated in a randomized clinical outcome trial in 10,000 high-risk patients with diabetes receiving high-intensity statin therapy. ${ }^{23}$

The failure of niacin to reduce ASCVD risk in patients with well-controlled LDL-C levels did not halt interest in HDL-C-raising therapies. Despite raising HDL-C level by as much as $130 \%$, several cholesteryl ester transfer protein (CETP) inhibitors have struggled to match the improvement in HDLC with clinical outcomes. Torcetrapib increased cardiovascular mortality due to mineralocorticoidmediated off-target effects, whereas dalcetrapib and evacetrapib demonstrated a neutral effect on cardiovascular outcomes. ${ }^{34}$ Only anacetrapib demonstrated a significant reduction in cardiovascular events, yet the benefit was modest and deemed insufficient by the sponsor to pursue FDA approval. ${ }^{35}$ The remaining hope for CETP inhibition lies in the Effect of Dalcetrapib vs Placebo on CV Risk in a Genetically Defined Population with a Recent ACS (Dal-GenE) trial, which is currently evaluating the effectiveness of dalcetrapib in a group of subjects with a particular gene variant called ADCY9 who had a $39 \%$ lower cardiovascular event rate compared to those without the gene variant in the dal-OUTCOMES trial. $^{36}$

Although the success of any of these novel therapies would provide benefit to patients, it will undoubtedly further complicate the management of dyslipidemia and cardiovascular risk reduction. Given the significant cost burden of novel therapies, such as the PCSK9 inhibitors, future guidelines will have to determine whether or not to factor in the costs of drug therapy in their guideline recommendations. Furthermore, there will predictably be a lack of head-to-head clinical trials to compare the effectiveness of non-statins. It is likely that patients with a high burden of atherogenic cholesterol despite maximally tolerated statin therapy may receive ezetimibe and/or a PCSK9 inhibitor, whereas patients with elevated TG levels may receive a TG-lowering therapy. An advantage of novel agents in the dyslipidemia environment is the broadening acceptance of new strategies, such as the potential role of antiinflammatory therapies (e.g., canakinumab), which may

This article is protected by copyright. All rights reserved. 
be prioritized over additional lipid-lowering therapies in patients with elevated C-reactive protein levels. ${ }^{37}$ Improving our understanding of lipid metabolic pathways may create new opportunities for personalized medicine and "omic" implications.

\section{Role of the Clinical Pharmacist}

The uncertainty surrounding appropriate treatment of residual cardiovascular risk emphasizes the need for clinical pharmacists who are adept at recognizing the niche benefits of nonstatin therapies. Inclusion of clinical pharmacists in team-based management of dyslipidemia is well established in the literature. A recent Cochrane analysis found that team-based intensification of care resulted in improved LDL-C level and adherence to lipid-lowering therapies. ${ }^{38} \mathrm{~A}$ key aspect of medication adherence is prescription affordability and access. Clinical pharmacists can help providers select statins of appropriate intensity while balancing out-of-pocket costs to the patient by suggesting less expensive generic options, therapeutic substitutions, and patient assistance programs. Patient adherence to statin therapy may also be affected by a drug's adverse effects. Clinical pharmacists can help the health care team identify potential drug-drug interactions and suggest appropriate alternatives before the patient experiences an adverse effect. Finally, if a patient experiences an adverse effect such as statin-associated muscle symptoms, clinical pharmacists can systematically evaluate the strength of causation and suggest appropriate mitigation strategies. Although many patients may experience statin-associated muscle symptoms, few patients are truly intolerant to statins; therefore, the clinical pharmacist can guide the patient toward optimally tolerated statin therapy and augment the regimen with appropriate non-statin therapies as necessary.

This article is protected by copyright. All rights reserved. 


\section{Conclusion}

Despite recent data demonstrating favorable outcomes with ezetimibe and evolocumab, maximally tolerated statin therapy should remain the initial approach to lowering LDL-C level and reduce ASCVD risk. Not all patients, however, will achieve treatment goals with statin therapy or tolerate higher statin doses. Given the available clinical outcomes data, ezetimibe and PCSK9 inhibitors should be considered in high-risk patients unable to tolerate recommended statin intensities or who fail to achieve treatment goals. Routine use of non-statins that primarily lower triglyceride levels are not currently recommended until results from ongoing clinical trials evaluating their use in combination with statin therapy are completed. Clinical pharmacists have a significant opportunity to help patients with dyslipidemia by identifying and resolving significant drug-drug interactions that may increase the risk of statin-related adverse effects, ensuring adherence, identifying solutions for barriers to medication access, and assisting the health care team on appropriate patient selection for non-statins.

\section{References}

1. Cholesterol Treatment Trialists' (CTT) Collaborators. The effects of lowering LDL cholesterol with statin therapy in people at low risk of vascular disease: metaanalysis of individual data from 27 randomised trials. Lancet 2012;380(9841):581-90.

2. Thompson PD, Panza G, Zaleski A, Taylor B. Statin-Associated Side Effects. J Am Coll Cardiol 2016;67(20):2395-410.

3. LaRosa JC, Grundy SM, Waters DD, et al. Intensive lipid lowering with atorvastatin in patients with stable coronary disease. N Engl J Med 2005;352:1425:35.

4. Stone NJ, Robinson JG, Lichtenstein AH, et al. 2013 ACC/AHA Guideline on the Treatment of Blood Cholesterol to Reduce Atherosclerotic Cardiovascular Risk in Adults. J Am Coll Cardiol 2014;63(25);2889-934.

This article is protected by copyright. All rights reserved. 
5. Third Report of the National Cholesterol Education Program (NCEP) Expert Panel on Detection, Evaulation, and Treatment of High Blood Cholesterol in Adults (Adult Treatment Panel III) final report. Circulation 2002;106:3142-421.

6. Jacobson TA, Ito MK, Maki KC, et al. National Lipid Association recommendations for patient-centered management of dyslipidemia: Part 1 - full report. J Clin Lipidol 2015;9(2):129-69.

7. Dixon DL, Trankle C, Buckley L, Parod E, Carbone S, Van Tassell BW, Abbate A. A review of PCSK9 inhibition and its effects beyond LDL receptors. J Clin Lipidol 2016;10(5):1073-80.

8. Cannon CP, Blazing MA, Giugliano RP, McCagg A, et al. Ezetimibe added to statin therapy after acute coronary syndromes. N Engl J Med 2015;372(25):238797.

9. Lloyd-Jones DM, Morris PB, Ballantyne CM, et al. 2016 ACC Expert Consensus Decision Pathway on the Role of Non-Statin Therapies for LDL-Cholesterol Lowering in the Management of Atherosclerotic Cardiovascular Disease Risk: A Report of the American College of Cardiology Task Force on Clinical Expert Consensus Documents. J Am Coll Cardiol 2016;68(1):92-125.

10. Sabatine MS, Giugliano RP, Keech AC, et al. Evolocumab and clinical outcomes in patients with cardiovascular disease. N Engl J Med 2017;376(18)1713-22.

11. Lloyd-Jones DM, Morris PB, Ballantyne CM, et al. 2017 Focused Update of the 2016 ACC Expert Consensus Decision Pathway on the Role of Non-Statin Therapies for LDL-Cholesterol Lowering in the Management of Atherosclerotic Cardiovascular Disease Risk. J Am Coll Cardiol 2017;70(14):1785-822.

12. Orringer CE, Jacobson TA, Saseen JJ, Brown AS, Gotto AM, Ross JL, Underberg JA. Update on the use of PCSK9 inhibitors in adults:

Recommendations from an Expert Panel of the National Lipid Association. J Clin Lipidol 2017; 11(4):880-90.

13. Rossebo AB, Pedersen TR, Boman $\mathrm{K}$, et al. Intensive lipid lowering with simvastatin and ezetimibe in aortic stenosis. N Engl J Med 2008;359:1343-56.

14. Baigent C, Landray M, Reith C, et al. The effects of lowering LDL cholesterol with simvastatin plus ezetimibe in patients with chronic kidney disease (Study of Heart and Renal Protection): a randomised placebo-controlled trial. Lancet 2011;377:2181-92.

15. Kastelein JJP, Akdim F, Stroes ESG, et al. Simvastatin with or without ezetimibe in familial hypercholesterolemia. N Engl J Med 2008;358(14):1431-43.

16. Toth PP, Maki KC. A Commentary on the implications of the ENHANCE (Ezetimibe and Simvastatin in Hypercholesterolemia Enhances Atherosclerosis

This article is protected by copyright. All rights reserved. 
Regression) Trial: Should ezetimibe move to the "Back of the Line" as a therapy for dyslipidemia? J Clin Lipidol. 2008;2(5):313-7.

17. Mascitelli L, Goldstein MR. Adding Ezetimibe to Simvastatin for the secondary prevention of cardiovascular disease: Is It Useful? J Am Coll Cardiol 2016;67(25):3025.

18. Navar A, Taylor B, Mulder H, et al. Association of prior authorization and out-ofpocket costs with patient access to PCSK9 inhibitor therapy. JAMA Cardiol 2017. doi: 10.1001/jamacardio.2017.3451. [Epub ahead of print]

19. Bonow RO, Harrington RA, Yancy CW. Cost-effectiveness of PCSK9 inhibitors: Proof in the modeling. JAMA Cardiol 2017. doi:10.1001/jamacardio.2017.3656. [Epub ahead of print]

20. Baum SJ, Toth PP, Underberg JA, Jellinger P, Ross J, Wilemon K. PCSK9 inhibitor access barriers-issues and recommendations: Improving the access process for patients, clinicians and payers. Clin Cardiol 2017;40(4):243-54.

21. Amgen. FDA approves Amgen's Repatha ${ }^{\circledR}$ (evolocumab) to prevent heart attack and stroke [press release]. December 1, 2017. Available from http://www.amgen.com/media/news-releases/2017/12/fda-approves-amgensrepatha-evolocumab-to-prevent-heart-attack-and-stroke/. Accessed December 7, 2017.

22. The ACCORD Study Group. Effects of combination lipid therapy in type 2 diabetes mellitus. N Engl J Med 2010;362(17):1563-74.

23. Kelly MS, Beavers C, Bucheit JD, Sisson EM, Dixon DL. Pharmacologic approaches for the management of patients with moderately elevated triglycerides (150-499 mg/dL). J Clin Lipidol 2017;11(4):872-9.

24. Elam MB, Ginsberg HN, Lovato LC, et al. Association of fenofibrate therapy with long-term cardiovascular risk in statin-treated patients with type 2 diabetes. JAMA Cardiol;2(4):370-80.

25. American Diabetes Association. Standards of medical care in diabetes-2017. Diabetes Care 2017;40(Suppl 1):S75-S88.

26. Yokoyama M, Origasa $\mathrm{H}$, Matsuzaki $\mathrm{M}$, et al. Effects of eicosapentaenoic acid on major coronary events in hypercholesterolaemic patients (JELIS): a randomised open-label, blinded endpoint analysis. Lancet. 2007;369(9567):1090-8.

27. Maki KC, Palacios OM, Bell M, Toth PP. Use of supplemental long-chain omega3 fatty acids and risk for cardiac death: An updated meta-analysis and review of research gaps. J Clin Lipidol 2017;11(5):1152-1160.e2.

28. Siscovick DS, Barringer TA, Fretts AM, et al. Omega-3 Polyunsaturated Fatty Acid (Fish Oil) Supplementation and the Prevention of Clinical Cardiovascular

This article is protected by copyright. All rights reserved. 
Disease: A Science Advisory from the American Heart Association. Circulation 2017;135(15):e867-84.

29. The HPS2-THRIVE Collaborative Group. Effects of Extended-Release Niacin with Laropiprant in High-Risk Patients. N Engl J Med 2014;371(3):203-12.

30. AIM-HIGH Investigators. Niacin in Patients with Low HDL Cholesterol Levels Receiving Intensive Statin Therapy. N Engl J Med 2011;365(24):2255-67.

31. Superko HR, Zhao X-Q, Hodis HN, Guyton JR. Niacin and Heart Disease Prevention: Engraving Its Tombstone Is a Mistake. J Clin Lipidol 2017. doi: 10.1016/j.jacl.2017.08.005. [Epub ahead of print]

32. Giugliano RP, Pedersen TR, Park JG, et al. Clinical efficacy and safety of achieving very low LDL-cholesterol concentrations with the PCSK9 inhibitor evolocumab: A prespecified secondary analysis of the FOURIER trial. Lancet. 2017;390(10106):1962-71.

33. Jellinger PS, Handelsman Y, Rosenblit PD, et al. American Association of Clinical Endocrinologists and American College of Endocrinology Guidelines for Management of Dyslipidemia and Prevention of Cardiovascular Disease. Endocr Pract 2017;23(Suppl 2):1-87.

34. Kosmas CE, Dejesus E, Rosario D, Vittorio TJ. CETP inhibition: Past failures and future hopes. Clin Med Insights Cardiol. 2016;10:37-42.

35. The HPS3/TIMI55-REVEAL Collaborative Group. Effects of anacetrapib in patients with atherosclerotic vascular disease. N Engl J Med 2017;377:1217-27.

36. Effect of Dalcetrapib vs Placebo on CV Risk in a Genetically Defined Population With a Recent ACS (dal-GenE). (2015). Retrieved from: https://clinicaltrials.gov/ct2/show/NCT02525939

37. Ridker PM, Everett BM, Thuren T, et al. Antiinflammatory therapy with canakinumab for atherosclerotic disease. N Engl J Med 2017;377:1119-31.

38. Van Driel ML, Morledge MD, Ulep R, Shaffer JP, Davies P, Deichmann R. Interventions to improve adherence to lipid-lowering medication. Cochrane Database Syst Rev 2016;12:CD004371. doi: 10.1002/14651858.CD004371.pub4.

This article is protected by copyright. All rights reserved. 
Table 1. Summary of Recent Guidelines and Recommendations on the Use of Non-Statins for Dyslipidemia Management

\begin{tabular}{|c|c|}
\hline Guideline & Recommendations \\
\hline $\begin{array}{l}2013 \text { ACC/AHA } \\
\text { Cholesterol } \\
\text { Guideline }^{4}\end{array}$ & $\begin{array}{l}\text { Non-statins should only be considered in high-risk patients (clinical ASCVD, } \\
\text { LDL-C } \geq 190 \mathrm{mg} / \mathrm{dL} \text {, diabetes mellitus) who have a suboptimal response to } \\
\text { statins and/or are intolerant to statin therapy } \\
\text { Preference was given to non-statins shown to reduce ASCVD in RCTs but } \\
\text { made no specific recommendations } \\
\text { Provided recommendations on only the safety of non-statins (BAS, ezetimibe, } \\
\text { fibrates, niacin, O3FA) } \\
\text { Referred readers to the } 2011 \text { AHA Statement regarding management of } \\
\text { elevated TG levels }\end{array}$ \\
\hline $\begin{array}{l}2014 \text { NLA Patient- } \\
\text { Centered } \\
\text { Recommendations }^{6}\end{array}$ & $\begin{array}{l}\text { Emphasized use of non-statins that lower atherogenic cholesterol in patients } \\
\text { not meeting treatment goals and/or are intolerant to statin therapy } \\
\text { Preference was given to non-statins shown to reduce ASCVD in RCTs but } \\
\text { made no specific recommendations } \\
\text { TG-lowering therapies (O3FA, fibrates, or niacin) recommended as } 1 \mathrm{st} \text { line if } \\
\text { TG } \geq 1000 \mathrm{mg} / \mathrm{dL} \text { or if TG } 500-999 \mathrm{mg} / \mathrm{dL} \text { in patients with a history of } \\
\text { pancreatitis. Statins recommended as } 1 \mathrm{st} \text { line if TG } 200-499 \mathrm{mg} / \mathrm{dL} \text {, but TG- } \\
\text { lowering therapies may be considered in patients who do not achieve their } \\
\text { non-HDL-C goal. }\end{array}$ \\
\hline $\begin{array}{l}2016 \text { Non-Statin } \\
\text { Expert Consensus } \\
\text { Decision Pathway }\end{array}$ & $\begin{array}{l}\text { Provided treatment goals for non-HDL-C and LDL-C (previously not included in } \\
\text { the } 2013 \text { ACC/AHA cholesterol guideline) } \\
\text { Ezetimibe generally considered as } 1 \text { st-line non-statin; BAS recommended as } \\
\text { an alternative for those intolerant to ezetimibe and with TG levels }<300 \mathrm{mg} / \mathrm{dL} \\
\text { PCSK9 inhibitors recommended as add on, or replacement, to ezetimibe in } \\
\text { patients with clinical ASCVD and/or baseline LDL-C } \geq 190 \mathrm{mg} / \mathrm{dL}\end{array}$ \\
\hline $\begin{array}{l}2017 \text { Focused } \\
\text { Update of the } 2016 \\
\text { Non-Statin Expert } \\
\text { Consensus } \\
\text { Decision Pathway }{ }^{11}\end{array}$ & $\begin{array}{l}\text { Provided treatment goals for non-HDL-C and LDL-C (previously not included in } \\
\text { the } 2013 \text { Guideline) } \\
\text { Ezetimibe generally considered as } 1^{\text {st }} \text {-line non-statin in patients with clinical } \\
\text { ASCVD but without other comorbidities (e.g., diabetes, recent ASCVD event, } \\
\text { poorly controlled ASCVD risk factors, continued cigarette smoking); BAS }\end{array}$ \\
\hline
\end{tabular}

This article is protected by copyright. All rights reserved. 


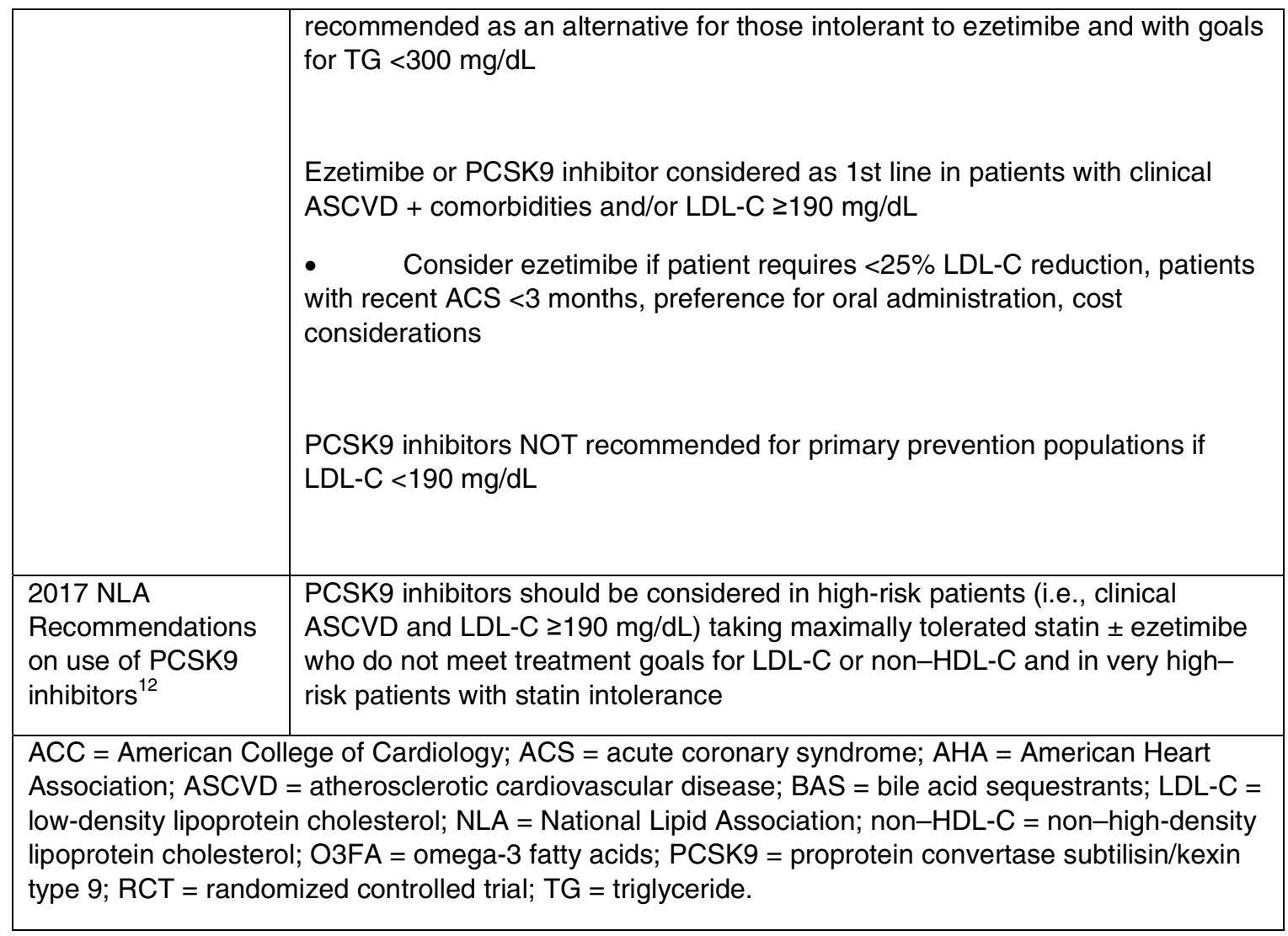

This article is protected by copyright. All rights reserved. 